\title{
An efficient hybrid reconfigurable wind gas turbine power management system using MPPT algorithm
}

\author{
Manjunath T. N. ${ }^{1}$, Mallikarjunaswamy S. ${ }^{2}$, Komala M. ${ }^{3}$, Sharmila N. ${ }^{4}$, Manu K. S. \\ ${ }^{1}$ Department of Information Science Engineering, BMS Institute of Technology and Management, Bengaluru India \\ ${ }^{2}$ Department of Electronics and Communication Engineering, JSS Academy of Technical Education, Bengaluru India \\ ${ }^{3}$ Department of Electronics and Communication Engineering, SJB institute of Technology, Bengaluru India \\ ${ }^{4}$ Department of Electrical and Electronics Engineering, RNS Institute of Technology, Bengaluru India \\ ${ }^{5}$ Department of Computer Science and Engineering, SJB institute of Technology, Bengaluru India
}

\section{Article Info}

Article history:

Received Jul 25, 2021

Revised Oct 6, 2021

Accepted Oct 14, 2021

Keywords:

Hybrid power system

Maximum power point tracker

Permanent magnet synchronous generator

Wind energy conversion system

Power management system

\begin{abstract}
To improve power management scheme in standalone mode using hybrid wind-gas turbine system. To reduce electrical fluctuations due to permanent magnet synchronous generator (PMSG) in wind turbine system. For power generation, the wind turbine system is a main source. When there is reduction in wind turbine power generation, then gas turbine gets activated immediately and produces the required electricity in effective manner. This reconfigurable power generation system is controlled by perturb and observe maximum power point tracking (P\&O_MPPT) algorithm. The proposed wind-gas power management system algorithm and device performance was analysed and simulated using MATLAB R2021a for various wind turbine experiment parameters. The simulation result shows that the proposed model and algorithm effectively meets the load demand when the wind turbine speed falls below the minimum required value.
\end{abstract}

This is an open access article under the CC BY-SA license.

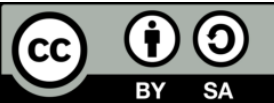

\section{Corresponding Author:}

Mallikarjunaswamy S

Department of Electronics and Communication Engineering

JSS Academy of Technical Education

JSSATE-B Campus, Dr. Vishnuvardhan Road, Uttarahalli - Kengeri Main Road

Srinivaspura-Post Bengaluru - 560060 Karnataka, India

Email: mallikarjunaswamys@jssateb.ac.in

\section{INTRODUCTION}

Constant attempts and efforts are made to meet the increase in power demand over the years. Conventional sources of power have issues of reserves and pollution. Solar and wind energy are enormously available and can be efficiently utilized. Hybrid power generation units have become an integral part of the conventional grid in recent times [1], [2]. The foremost goals of HPSs' is such that to decrease zero power intermissions, lessen the price \& deliver a consistent feed. The power system of wind utilized in our work comprises a diode which is a bridge rectifier and also a permanent magnet synchronous generator (PMSG), a wind turbine, a power-managed voltage source inverter a DC to DC boost converter. Resultant power which is generated from the PMSG is initially transformed to dc \& after that, it is supplied to the grid. The transformations are accomplished at the factor of unity power $\&$ the voltage of dc-link is retained as fixed. Nevertheless, when speed of the wind drops lower than the minimum needed a minor gas turbine model is presented as a hold up or a backup source to sustain electricity of a nonstop stream mode [3]-[5]. The power of wind which is maximum is extracted from the wind power system controller and it supplies to the given grid with a worthy quality [6], [7]. A flow controller of power is utilized to maintain the supplied electricity 
from both sources of power. Mainly the request must be fulfilled by the power system of wind due to the ensuing benefits of the given environment. The surplus energy which comes through wind turbine shall be deposited in the electrolyze scheme. Once the speed of the wind is less than minimum, then there will be a gas-turbine system power which is supplemented sufficiently as per the requirement all through this situation [8], [9].

\section{HYBRID RECONFIGURABLE WIND-GAS TURBINE POWER SYSTEM}

This structure is a combination of a wind energy conversion scheme complemented alongside a gas turbine structure utilized in high \& intermediate applications along with an electrolyze scheme for high applications and also for storing energy in an electrolyze system [10]. A blend of such kind of sources will actually assure an incessant power feed. The whole system diagram is depicted in Figure 1.

In these kind of hybrid amenities, the wind turbine precedence must be set [11], [12]. Once speed of the wind drops lower than the minimum needed, a regulating signal is directed towards the gas-turbine to instantly generate the anticipated electricity, The surplus energy which is generated through wind turbine shall be deposited in the electrolyze system. This shall be completed by the algorithm of power managing as shown in the flow diagram of Figure 2.

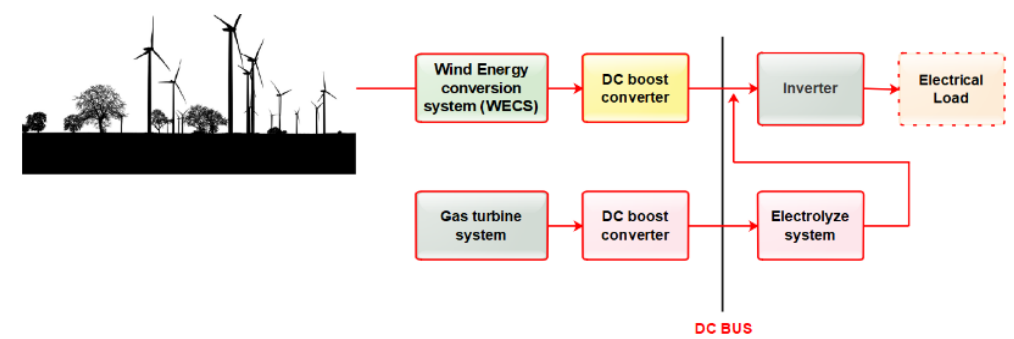

Figure 1. Functional block diagram of hybrid reconfigurable wind-gas turbine power system

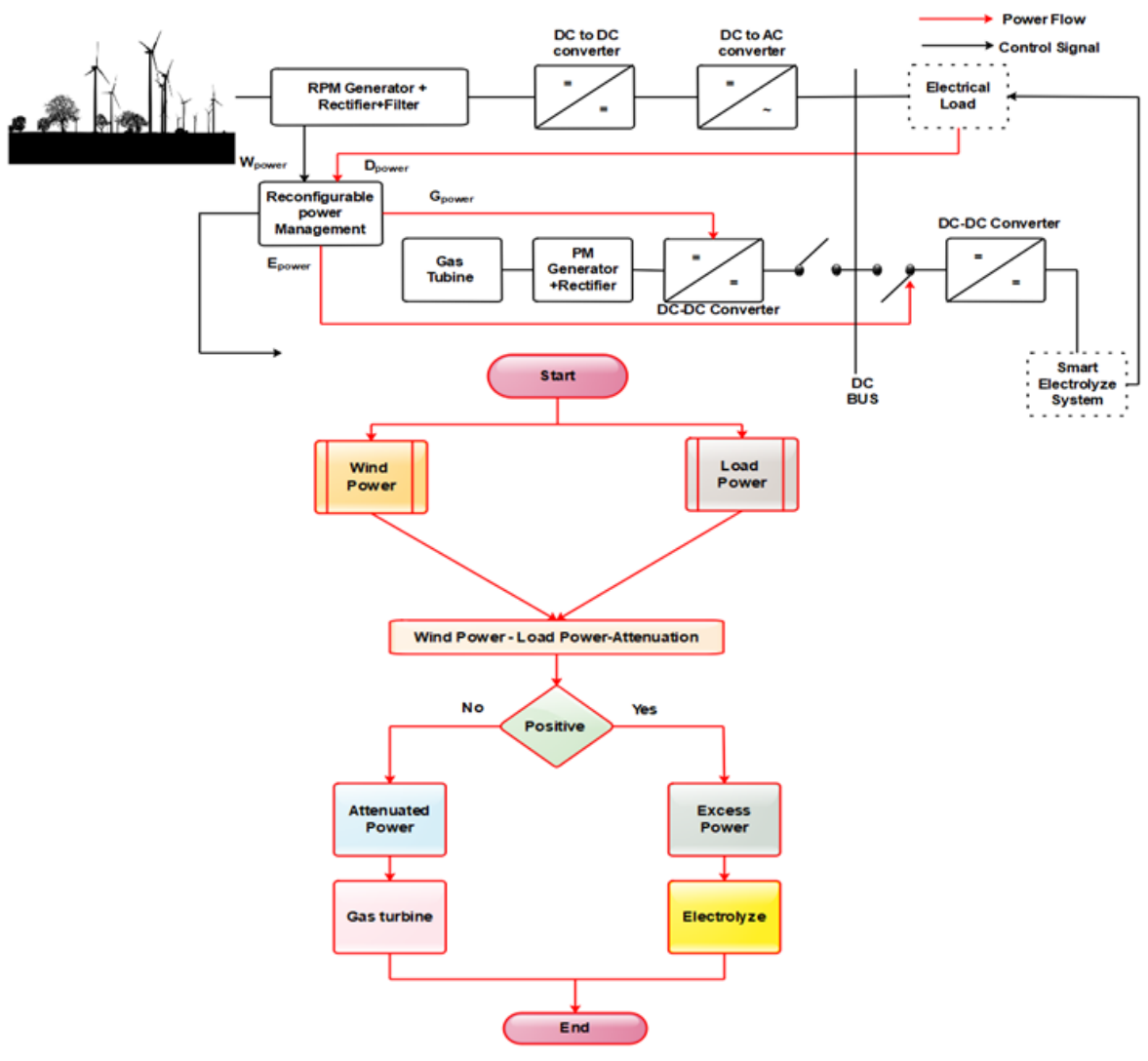

Figure 2. Proposed hybrid power management architecture 


\subsection{Conversion management scheme of wind turbine}

Figure 1 shows the function block diagram of hybrid reconfigurable wind gas turbine power system. This scheme of wind generator is designed by a stable pitch wind turbine, a passive rectifier, a DC to DC voltage source inverter and parallely a gas turbine system which is connected to the wind turbine system to generate uninterrupted power supply to meet the load requirement.

\subsection{Mathematical model of wind turbine system}

The blades which are present on a wind turbine will mine the stream of energy from moving \& supply it to the rotor of an electric generator through a gear box [13], [14]. The power of wind is calculated using (1).

$$
P_{w}=\frac{1}{2} \beta D W_{S}^{3}
$$

Where, ' $\beta$ ' denotes the air density that differs with temperature $\&$ pressure of air. Here the $P_{c}$ represents the power coefficient is generally specified as a function of the tip speed ratio, D presents the wind tubine blade rotating direction and $\rho$ which is the pitch angle of blade [15], [16].

The angle which is amid the blade cross-section chord \& plane of rotation is called the pitch angle. The tip speed ratio of a specified wind turbine is given in (2).

$$
\gamma=\frac{t_{v}}{W_{s 1}}=\frac{r A_{r}}{W_{s 1}}
$$

Where $A_{r}$ is identified as angular velocity of the rotor, $W_{s 1}$ is described as wind speed, $\mathrm{r}$ is resperesented as radius of rotor in meters and $t_{v}$ is described as blade pitch tangential velocity [17], [18].

For the wind turbine utilised here in our research work, $P_{c}$ as a function of $\gamma$ is specified through the (3) and (4).

$$
P_{c}=0.045-0.125 \gamma+0.156 \gamma^{2}-0.072 \gamma^{3}+0.015 \gamma^{4}-0.0007 \gamma^{5}+0.016 \gamma^{6}
$$

The wind turbines output power $\left(P_{\text {wout }}\right)$ is computed as given in (4).

$$
P_{\text {wout }}=\frac{1}{2} P_{c}(\gamma) D W_{s}^{3}
$$

The rotor speed of the given generator versus mechanical power for various speeds of wind is depicted in Figure 2. The power which is obtained through the wind is actually maximized once $P_{c}$ is at its maximum. This happens at a distinct value of the ratio of $\gamma$, tip speed. Therefore, for every speed of wind rotor speed is there which is optimum, such that maximum power is obtained through the wind. Hence in case speed of wind is presumed to be fixed, the value of $P_{c}$ hinge on the speed of rotor of the wind turbine. So, power output of the turbine is regulated by regulating the rotor speed [19].

\section{INTEGRATED PMSG BASED WIND TUBINE ELECTRICAL SYSTEM}

The diagram of the integrated wind-gas turbine electrical system is depicted in Figure 3 . The transformation of the wind power to the corresponding mechanical power in the given shaft of the rotor is done by the wind turbine. It is later transformed to electricity utilizing a PMSG. With the help of a 3-phase diode bridge rectifier, the output voltage is resolved. The converter of dc to dc is utilised to regulate the $V_{d c}$ through capacitor $C_{1}$. The MPPT regulator supplies a voltage which is paralleled to the $V_{d c}$ actual value. The outcome is supplied to a PI regulator, the output of which is paralleled to a triangular waveform in order to find at what time to make the dc dc boost converter switch OFF or ON [20]. The PWM inverter voltage source interacts with the scheme of wind turbine along with the power grid. It functions in a way that the amplitude of the output current differs so as to retain fixed $V_{0}$, the dc voltage through the $C_{0}$ capacitor [21]. 


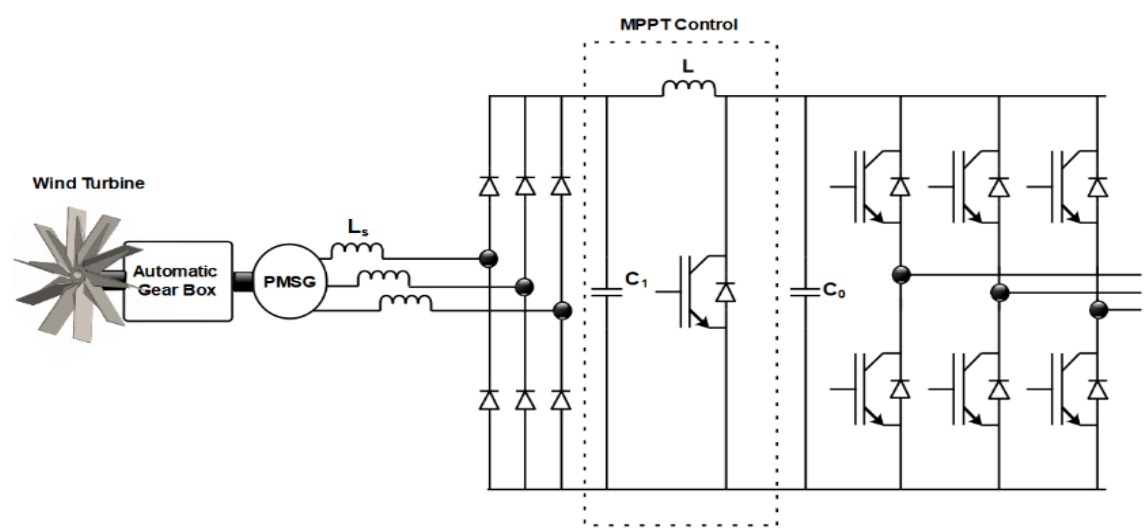

Figure 3. Integrated PMSG based wind energy conversion system (WECS)

\subsection{Algorithm of maximum power tracking}

Owing to its categorical features, the turbines of wind could be regulated to produce maximum power by means of search control approaches [22], [23]. Prior to understanding the maximum power tracing regulator, it is significant to know the fundamental physics of the structure. The mechanical power created is shown by (5).

$$
P_{m}=T_{m}(s) A_{R}(s)
$$

Where $P_{m}$ is represents the mechanical power and $T_{m}$ is identified as a mechincal torque, for ease, the produced electric power of a Solitary-phase generator is shown by (6).

$$
P_{\text {ele }}(s)=V_{g}(s) I_{g}(s)
$$

Where $V_{g}$ is presented generated voltage and $I_{g}$ is described as a generated current. Consider there is no attenuation in system, then the equation (6) can be represented as given in (7).

$$
T_{m}(s) \cdot A_{R}(s)=V_{g}(s) I_{g}(s)
$$

The fundamental electrical \& motion equations are represents [8]-[11]:

$$
\begin{aligned}
& T_{e l e}=\tau I_{g} I_{f c} \\
& I_{g}=\frac{V_{g}-E_{g}}{A_{\text {res }}} \\
& E_{g}=\tau I_{g} A_{\text {ele }}
\end{aligned}
$$

Where $T_{e l e}$ is identified as Electrical torque, $I_{f c}$ is described as field current, $E_{g}$ is represents as generated armature voltage , $\tau$ is described as torque nut factor, $A_{\text {ele }}$ is represented electrical angular speed and $A_{\text {res }}$ is identified as armature resistance. Electrical angular speed is given in (11).

$$
A_{\text {ele }}=\frac{P}{2} A_{R}
$$

Where $\mathrm{p}$ is the number poles of the generator. The resultant (12) obtained due to mean of (3) to (11).

$$
P_{\text {ele }}=\frac{A_{R} \tau I_{f c}}{A_{\text {res }}}\left(V_{g}-\tau I_{f c} A_{\text {ele }}\right)
$$

For a given diode rectifier, $V_{d c}$, the dc output voltage is relative to $V$, the generator phase voltage and (12) can be represented as given (13), therefore Maximum power generated at $\frac{d P_{\text {ele }}}{d V_{d c}}=0$

$$
P_{\text {ele }}=\frac{A_{R} \tau I_{f c}}{A_{\text {res }}}\left(V_{d c}-\tau I_{f c} A_{\text {ele }}\right)
$$


From (13) it is perceived that the power mined through the wind could be regulated by differing the bus voltage of dc, that is normally a function of $I_{f c}$ and $A_{\text {ele }}$. Seeing the features of wind turbine depicted in Figure 2, the maximum power point is got by the condition represented in (14)

$$
\frac{d P_{m}}{d A_{r}}=0
$$

Then 14 can be represented as shown in (15).

$$
\frac{d P_{m}}{d A_{R}}=\frac{d P_{m}}{d V_{d c}} \frac{d V_{d c}}{d A_{\text {ele }}} \frac{d A_{\text {ele }}}{d A_{R}}=0
$$

When maximum power point reached then (15) can be represented as represented in (16)

$$
\frac{d p_{m}}{d V_{d c}}=0
$$

The function $P_{m}\left(V_{d c}\right)$ consists of a one point such that maximum power extraction is attained. This again implies that the supreme power could be traced by probing the corrected dc power, more than the situations of environment, like direction \& speed of wind. The algorithm of MPPT is represent from (4) to (8). We can start the maximum power probing procedure by fixing a $V_{r e f}$, which is the random dc side reference of voltage. The regulator will then process the voltage $\&$ dc side current, $\&$ computes the initial electric power $P_{o}=V_{d c} I_{d c}$. After this, the $V_{r e f}$ voltage reference is upsurged by $\Delta V_{d c}$ as given in 17 .

$$
V_{r e f}(\tau)=V_{r e f}(\tau-1)+\Delta V_{d c}
$$

The dc power is then computed with $P(\tau)=V_{d c}(\tau) I_{d c}(\tau)$

In case $P(\tau)$ is larger than $P(\tau-1)$ that means the maximum power point hasn't stood touched hence, the voltage reference requires to be up surged by $\Delta V_{d c} \&$ it requires the dc power to be paralleled. This procedure shall recur till maximum power is got. Also, in case $(\tau)<P(\tau-1)$, The dc or the reference of voltage is further reduced by $\Delta V_{d c}$.

\section{INTEGRATED PMSG BASED GAS TURBINE ELECTRICAL SYSTEM}

The rotor motion \& non-stop power cycle of the gas turbine offers numerous benefits compared to other kinds of heat engines, along with moderately vibration less process. The one-shaft gas turbine has a fully integrated prime mover which is self-contained. This remarkably compact gas turbine has 3 fundamental phases: combustor, turbine \& compressor [24]-[26]. In this work the gas system is reflected as apparatus providing electrical power at its output. Hence no subsequent particulars are given around it. Figure 2 depicts that a DC output which is variable in nature of the Wind turbine is interacted by a $450 \mathrm{~V}$ DC bus. The gas system power booster \& WECS converters are given by (18), (19), (20), (21).

$$
\begin{aligned}
& \frac{B_{v o l}}{W_{v o l}}=\frac{1}{1-\tau_{w}} \\
& \frac{B_{v o l}}{G_{v o l}}=\frac{1}{1-\tau_{G}} \\
& \tau_{W}=\theta_{w} * F_{W} \\
& \tau_{G}=\theta_{G} * F_{G}
\end{aligned}
$$

Where $B_{v o l}$ is represents voltage carried in a bus, $W_{v o l}$ is decribed the voltage generated by wind turbine, $G_{v o l}$ is identified as voltage generated by gas turbine, $\tau_{w}$ is represented as nut factor of wind tutbine, $\tau_{G}$ is nut factor of gas tutbine, $\theta$ is the chopping pulse width and $f$ is the chopping frequency. Figure 4 depicts the Electrical circuit belonging to the DC to DC boost converter [27]-[29]. 


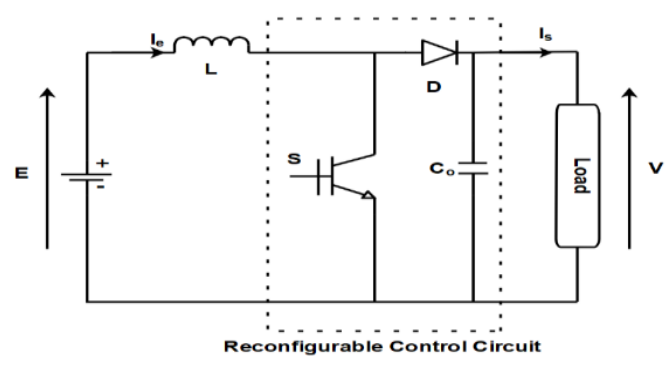

Figure 4. Reconfigurable DC power boost converter

\section{THE POWER BALANCED ELECTROLYZE SYSTEM}

This system is made up of the stacks of Electrolyze and a tank of hydrogen. As per faraday's law and considering account parasitic losses of current, the genuine hydrogen generation rate $H_{p}(\mathrm{~mol} / \mathrm{s})$ of a stack of electrolyze is shwon in (22) [30]-[32].

$$
H_{p}=\frac{\eta_{F} S_{c} I_{E Z}}{2 F}
$$

Where $S_{c}$ number of series connected cells, $I_{E Z}$ is the Electrolyzer input current (A), $\eta_{F}$ is Faraday's efficiency and $\mathrm{F}$ is Faraday constant $(\mathrm{C} / \mathrm{kmol})$ [33]. Normally, in the tank there will be storage gases which are shown by the association amongst temperature, gas moles and pressure. The hydrogen tank's state of charge is estimated using (23).

$$
H_{\text {soc }} \%=\frac{\int\left(H_{p}-H_{p}^{\text {in }}\right) * 100}{S_{H \max }}
$$

Where $S_{\text {Hmax }}$ is represented the maximum number of hydroges moles.

\section{RESULTS AND DECUSSION}

\subsection{Simulation wind-gas MPPT results}

The wind turbine summary is depicted in Figure 5 (a) and the output of simulation of the WECS with the given algorithm of MPPT are depicted in Figure 5 (b) and Figure 5 (c). We observe from that by the upsurge in the speed of the wind, the power supplied to the grid too upsurges that is shown by a raise in magnitude of PMSG phase current at Figure 5 (c). When $\mathrm{t}=12 \mathrm{~s}$, the speed of wind is altered from 6 to $8 \mathrm{~m} / \mathrm{s}$ in stage, however tip-speed ratio is sustained at $\mathrm{Cp}$ maximum in firm state circumstances as depicted in Figure 5 (b). It is observed that the regulator is competent to look for maximum power \& retain the wind turbine power coefficient, near to its maximum.

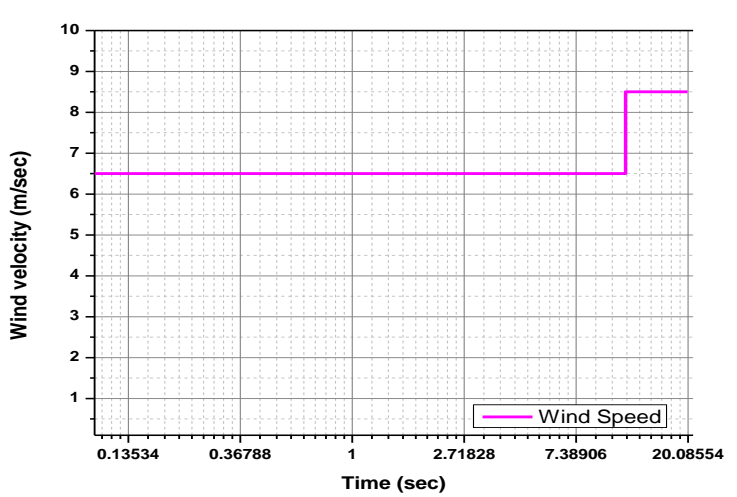

(a)

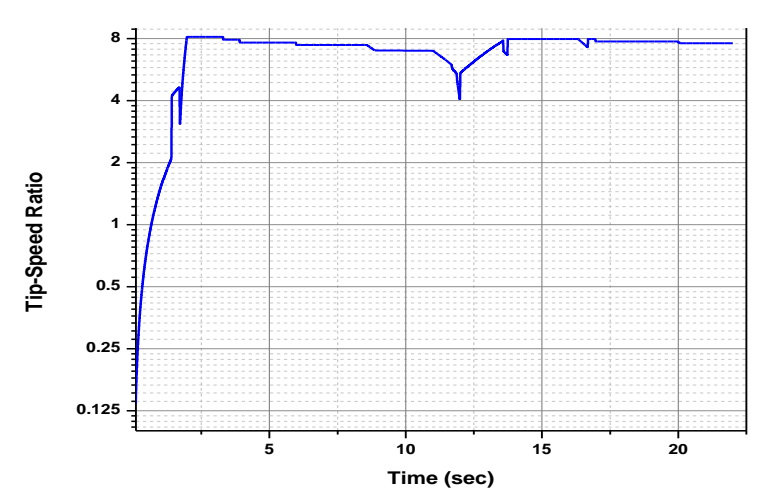

(b)

Figure 5. (a) Simulated analysis of wind turbine speed, (b) analysis wind turbine tip speed using MPPT algorithm 


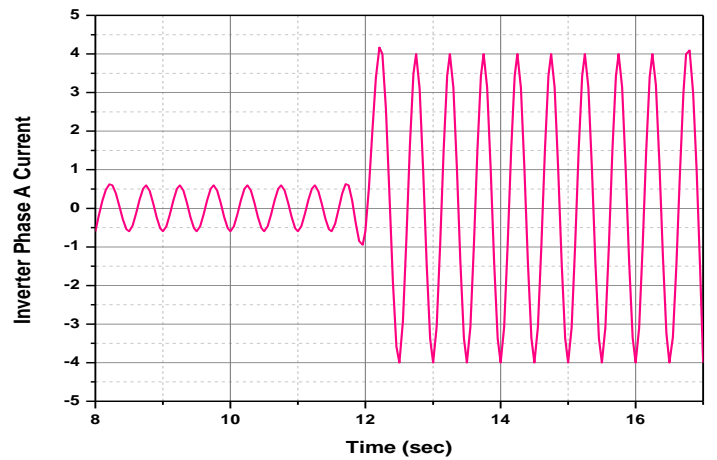

(c)

Figure 5. (c) analysis wind turbine inverter phase current using MPPT algorithm (continue)

\subsection{Simulation results of hybrid reconfigurable power management system}

The power maintenance flow diagram is shown by Figure 2. There was no consideration of the permanent magnet generator \& the gas-turbine. The Rectifier group of the Turbine-Generator is modelled like a modest DC source which inserts the asked DC power inside the DC bus as depicted in Figure 2. The utilized profile of the speed of wind is represented in Figure 6. The equivalent attained power of wind turbine is depicted in Figure 7. Choose The load demand power profile is to be $2.6 \mathrm{~kW}$ with respect to the time varied in between 2 and $6 \mathrm{~s}$, then $1.2 \mathrm{~kW}$ with respect to the time varied in between 6 and $10 \mathrm{~s}$, then $2.6 \mathrm{~kW}$ with respect to the time varied in between 9 and $14 \mathrm{~s} \&$ finally $1.6 \mathrm{~kW}$ for the balance simulation time as represented in Figure 8.

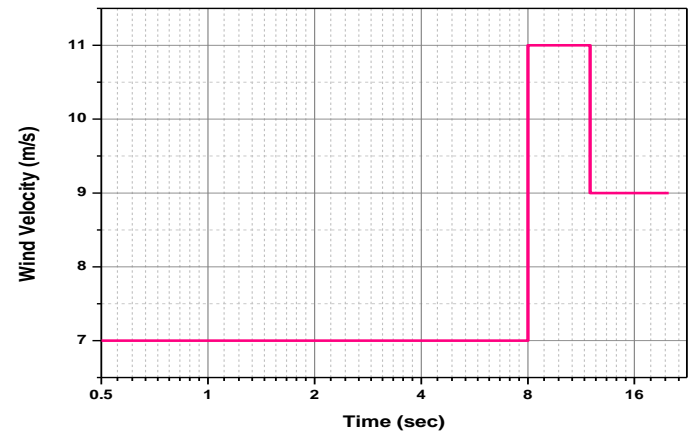

Figure 6. summary of wind speed profile

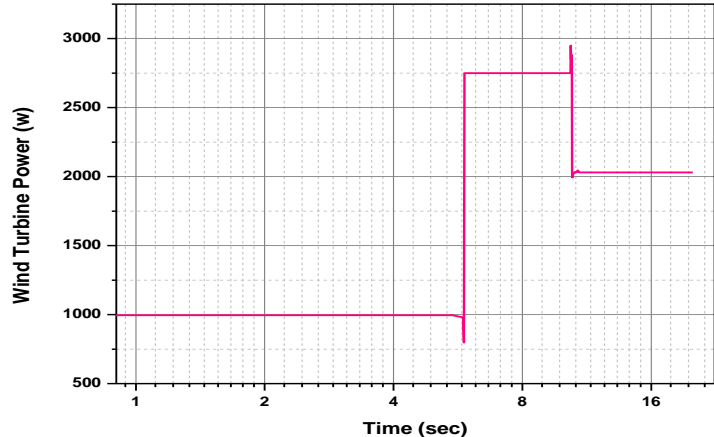

Figure 7. Summary of wind turbine power

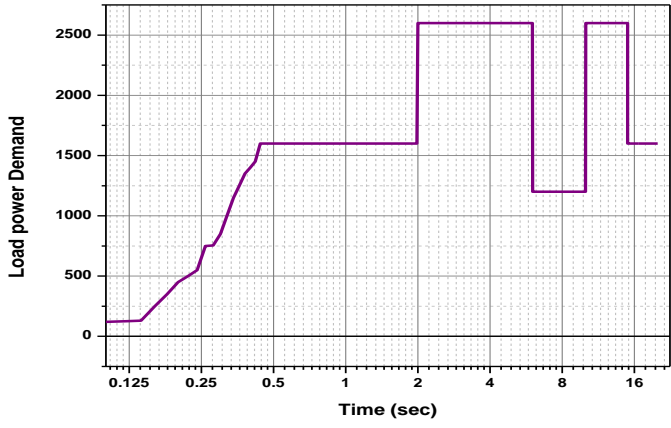

Figure 8. Summary of load power demand

The outcomes of simulation of the managing algorithm for diverse profiles of speed of wind are represented in Figure 9 and Figure 10 for the gas turbine and electrolyze system powers correspondingly. We notice seeing the graphs that among $2 \mathrm{~s}$ and $6 \mathrm{~s}$, the power of wind turbine $(1.2 \mathrm{KW})$ is lesser than the load

An efficient hybrid reconfigurable wind gas turbine power management system ... (Manjunath T N) 
demand $(2.6 \mathrm{KW})$. The simulation of gas turbine is done by the difference $(1.6 \mathrm{KW})$ so as to balance the load. The similar mechanism is for the electrolyze system that is charging at $8 \mathrm{~s}$ and $15 \mathrm{~s}$ after the demand is lesser than the wind power. The opposite condition where it supplies power to the load isn't depicted. But the Electrolyze is favoured to the gas turbine till the deceasing of the power in the stacks.

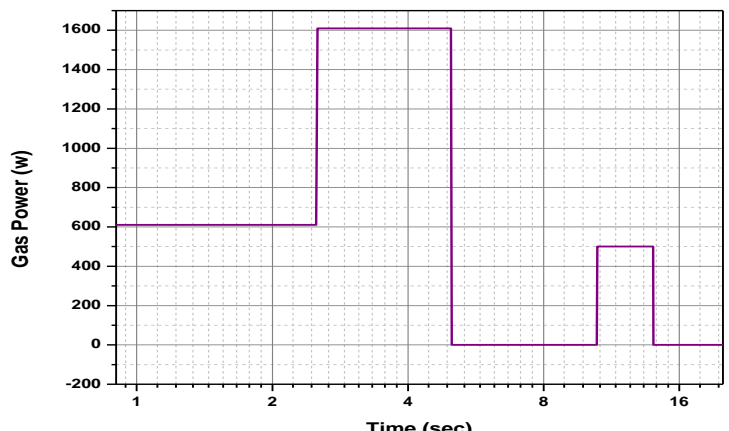

Figure 9. Gas tubine power execution summary

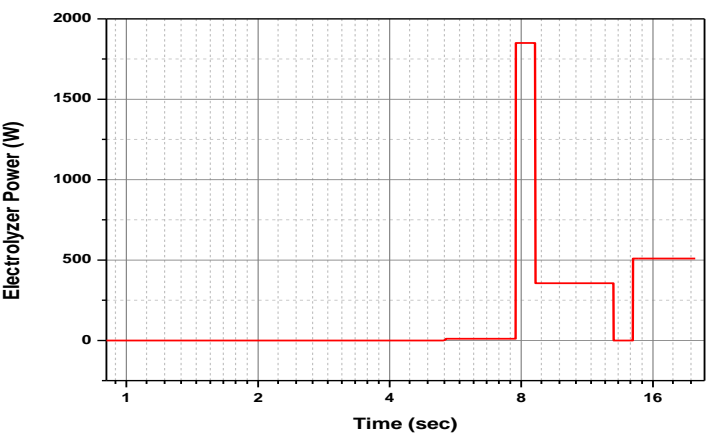

Figure 10. Electrolyze system power execution summary

\section{CONCLUSION}

The proposed method is implemented using hybrid reconfigurable wind and gas turbine model through P\&O MPPT algorithm. The maximum power has been extracted from air stream for any given value of wind speed independent of wind or rotor speed by the proposed algorithm. This is validated by the analysis and simulation. It effectively generates the required power during low wind speed or rotor speed. The proposed hybrid power management scheme offers an efficient synchronization with wind turbine, gas turbine and electrolyze power system with respect to required load demand. Since wind energy is dilute and intermittent, to ensure reliable supply of demand, a gas turbine and an electrolyze system is incorporated to hybridize the system and controlled using power flow control techniques. For a hybrid power system, the proposed power flow control and management algorithm is found to be suitable through analysis and simulation results. The Scope for improvement can include investigations on the fuel-to-power efficiency of the gas turbine. For instance, judicial use of gas is possible by controlling the operating temperature, which makes the operation cost-effective.

\section{ACKNOWLEDGEMENTS}

The authors would like to thank BMS Institute of Technology and Management, Bangalore, JSS Acadecmy of Technical Education, Bengaluru, Visvesvaraya Technological University (VTU), Belagavi and Vision Group on Science and Technology (VGST) Karnataka Fund for Infrastructure strengthening in Science \& Technology Level - 2 sponserd "Establishment of Renewable Smart Grid Laboratory" for all the support and encouragement provided by them to take up this research work and publish this paper.

\section{REFERENCES}

[1] C. Jung, D. Schindler, "Modeling wind turbine-related greenhouse gas payback times in Europe at high spatial resolution," Energy Conversion and Management, vol. 243. pp 1-32, 2021, doi: 10.1016/j.enconman.2021.114334

[2] Q. Yu, Y. Liu, Z. Jiang, L. Li, Y. Zhang, and M. Guo, "Study of offshore wind power penetration rate in gas turbine generator platform power grid," Energy Reports, vol 7. pp 141-146, 2020, doi: 10.1016/j.egyr.2021.02.011.

[3] R. Bhandari, B. Kumar, and F. Mayer, "Life cycle greenhouse gas emission from wind farms in reference to turbine sizes and capacity factors," Journal of Cleaner Production, vol 277. pp 1-9, 2020, doi: 10.1016/j.jclepro.2020.123385.

[4] L. Ju, Q. Tan, R. Zhao, S. Gu, Jiaoyang, and W. wang, "Multi-objective electro-thermal coupling scheduling model for a hybrid energy system comprising wind power plant, conventional gas turbine, and regenerative electric boiler, considering uncertainty and demand response," Journal of Cleaner Production, vol 237. pp 1-26, 2019, doi: 10.1016/j.jclepro.2019.117774.

[5] F. Gao, "Individual pitch control of windturbine based on blade element theory," International Conference on Automatic Control and Artificial Intelligence (ACAI 2012), pp. 1218-1221, 2012, doi: 10.1049/cp.2012.1198.

[6] S. Mallikarjunaswamy, N. Sharmila, D. Maheshkumar, M. Komala and H. N. Mahendra, "Implementation of an effective hybrid model for islanded microgrid energy management," Indian Journal of Science and Technology, vol 13, pp. 2733-2746, 2020, doi: 10.17485/IJST/v13i27.982. 
[7] S. Shivaji, K. R. Nataraj, S. Mallikarjunaswamy, and K. R. Rekha, "Design and implementation of reconfigurable DCT based adaptive PST techniques in OFDM communication system using interleaver encoder," Indian Journal of Science and Technology, vol. 13, no. 29, pp. 3008-3020, 2020, doi: 10.17485/IJST/v13i29.976.

[8] S Mallikarjunaswamy, K. R. Nataraj and K. R. Rekha, "Design of High-Speed Reconfigurable Coprocessor for Next-Generation Communication Platform," Emerging Research in Electronics, Computer Science and Technology, pp. 57-67, 2014, doi: 10.1007/978-81-322-1157-0_7.

[9] S Chaitra, V. Rekha, A. M. Harisha, S. Mallikarjunaswamy, N. Sharmila, H. N. Mahendra, "A comprehensive review of parallel concatenation of LDPC code techniques," Indian Journal of Science and Technology, vol. 14, no. 5, pp. 527-539, 2021, doi: 10.17485/IJST/v14i5.2171.

[10] T. Rösmann and S. Soter, "Regenerative Operation of DC-Series Machines in Pitchsystems for Multimegawatt Windturbines," 2008 IEEE Industry Applications Society Annual Meeting, 2008, pp. 1-7, doi: 10.1109/08IAS.2008.204.

[11] Yousef N. Dabwan, Gang Pei, Trevor Hocksun Kwan, Bin Zhao, "An innovative hybrid solar preheating intercooled gas turbine using parabolic trough collectors," Renewable Energy, vol. 179 , pp. 1009-1026, 2021, doi: 10.1016/j.renene.2021.07.057.

[12] S. Wang, W. Sicong, and J. Liu, "Response to 'Life-cycle green-house gas emissions of onshore and offshore wind turbines," Journal of Cleaner Production, vol 219, pp. 804-810, 2019, doi: 10.1016/j.jclepro.2018.11.031.

[13] M. Bianchi, L. Branchini, A. D. Pascale, A. Peretto, F. Melino, V. Orlandi, "Pump Hydro Storage and Gas Turbines Technologies Combined to Handle Wind Variability: Optimal Hydro Solution for an Italian Case Study," Energy Procedia, vol 82, pp. 570-576, 2015, doi: 10.1016/j.egypro.2015.11.872.

[14] H. Alphan, "Modelling potential visibility of wind turbines: A geospatial approach for planning and impact mitigation," Renewable and Sustainable Energy Reviews, vol 152, no. 3, pp. 270-288, 2021, doi: 10.1016/j.rser.2021.111675.

[15] S. Pooja, and S. Mallikarjunaswamy, "Adaptive Sparsity through Hybrid Regularization for Effective Image Deblurring," Indian Journal of Science and Technology, vol 14, no. 24, pp 2051-2068, 2021, doi: 10.17485/IJST/v14i24.604.

[16] T. A. Madhu, M. Komala, V. Rekha, S. Mallikarjunaswamy, N. Sharmila, and P. Pooja, "Design of fuzzy logic controlled hybrid model for the control of voltage and frequency in microgrid," Indian Journal of Science and Technology, vol 13, no. 35, pp. 3612-3629, 2020, doi: 10.17485/IJST/v13i35.1510.

[17] G. Guandalini, S. Campanari, and M. C. Romano, "Power-to-gas plants and gas turbines for improved wind energy dispatchability: Energy and economic assessment," Applied Energy, vol 147, pp. 117-130, 2015, doi: 10.1016/j.apenergy.2015.02.055.

[18] J. B. Greenblatt, S. Succar, D. C. Denkenberger, R. H. Williams, and R. H. Socolow, "Baseload wind energy: modeling the competition between gas turbines and compressed air energy storage for supplemental generation," Energy Policy, vol, 35, no. 3, pp. 1474-1492, 2007, doi: 10.1016/j.enpol.2006.03.023.

[19] H. Mohamadi, A. Saeedi, Z. Firoozi, S. S. Zangabadi, and S. Veisi, "Assessment of wind energy potential and economic evaluation of four wind turbine models for the east of Iran," Heliyon, vol 7, no. 6, pp. 1-10, 2021, doi: 10.1016/j.heliyon.2021.e07234.

[20] M. Bourhis, M. Pereira, F. Ravelet, I. Dobrev, "Innovative design method and experimental investigation of a small-scale and very low tip-speed ratio wind turbine", Experimental Thermal and Fluid Science, vol. 130, pp. 3860-3866, 2020, doi: 10.1016/j.expthermflusci.2021.110504.

[21] Y. Baala, and S. Bri, "Torque estimator using MPPT method for wind turbines," International Journal of Electrical and Computer Engineering, vol 10, no. 2, pp. 1208-1219, 2020, doi: 10.11591/ijece.v10i2.pp1208-1219.

[22] Y. Hocini, A. Allali, and H. M. Bouloiba, "Power fuzzy adaptive control for wind turbine," International Journal of Electrical and Computer Engineering, vol 10, no. 5, pp 5262-5273, 2020, doi: 10.11591/ijece.v10i5.pp52625273.

[23] A. K. Ermeey, M. M. Taib, A. R. Nasran, and Y. M. Yushafizee, "A vertical wind turbine monitoring system using commercial online digital dashboard," International Journal of Electrical and Computer Engineering, vol. 10, no. 5, pp. 5131-5138, 2020, doi: 10.11591/ijece.v10i5.pp5131-5138.

[24] B. Rached, M. Elharoussi, and E. Abdelmounim, "Design and investigations of MPPT strategies for a wind energy conversion system based on doubly fed induction generator," International Journal of Electrical and Computer Engineering, vol. 10, no. 5, pp. 4770-4781, 2020, doi: 10.11591/ijece.v10i5.pp4770-4781.

[25] H. Balaghi Enalou and E. A. Soreshjani, "A Detailed Governor-Turbine Model for Heavy-Duty Gas Turbines With a Careful Scrutiny of Governor Features," IEEE Transactions on Power Systems, vol. 30, no. 3, pp. 1435-1441, 2015, doi: 10.1109/TPWRS.2014.2342253.

[26] F. Kong, C. Dong, X. Liu and H. Zeng, "Quantity Versus Quality: Optimal Harvesting Wind Power for the Smart Grid," Proceedings of the IEEE, vol. 102, no. 11, pp. 1762-1776, 2014, doi: 10.1109/JPROC.2014.2359448.

[27] M. Cirrincione, M. Pucci and G. Vitale, "Growing Neural Gas-Based MPPT of Variable Pitch Wind Generators With Induction Machines," IEEE Transactions on Industry Applications, vol. 48, no. 3, pp. 1006-1016, 2012, doi: 10.1109/TIA.2012.2190964.

[28] M. Cirrincione, M. Pucci and G. Vitale, "Neural MPPT of Variable-Pitch Wind Generators With Induction Machines in a Wide Wind Speed Range," IEEE Transactions on Industry Applications, vol. 49, no. 2, pp. 942-953, 2013, doi: 10.1109/TIA.2013.2242817.

[29] N. Troy, D. Flynn and M. O. Malley, "Multi-Mode Operation of Combined-Cycle Gas Turbines With Increasing Wind Penetration," IEEE Transactions on Power Systems, vol. 27, no. 1, pp. 484-492, 2012, doi: 10.1109/TPWRS.2011.2163649. 
[30] P. Kala, and S. Arora, "A comprehensive study of classical and hybrid multilevel inverter topologies for renewable energy applications," Renewable and Sustainable Energy Reviews, vol. 76, pp. 905-931, 2017, doi: doi: 10.1016/j.rser.2017.02.008

[31] P. García-Triviño, A. José Gil-Mena, F. Llorens-Iborra, C. Andrés García-Vázquez, L. M. Fernández-Ramírez, and F. Jurado, "Power control based on particle swarm optimization of grid-connected inverter for hybrid renewable energy systeme," Energy Conversion and Management, vol. 91, pp. 83-92, 2015, doi: 10.1016/j.enconman.2014.11.051.

[32] K. Moutawakkil, and S. Elster, "RE hybrid systems: Coupling of Renewable Energy Sources on the AC and DC Side of the Inverter," Refocus, vol. 7, no. 5, pp. 46-48, 2006, doi: 10.1016/S1471-0846(06)70698-9.

[33] E. Najafi, and N. Prabaharan, "5 - Multilevel inverters for photovoltaic energy systems in hybrid-renewable energy systems," Hybrid-Renewable Energy Systems in Microgrids, pp 81-96, 2018, doi: 10.1016/B978-0-08-1024935.00005-4.

\section{BIOGRAPHIES OF AUTHORS}
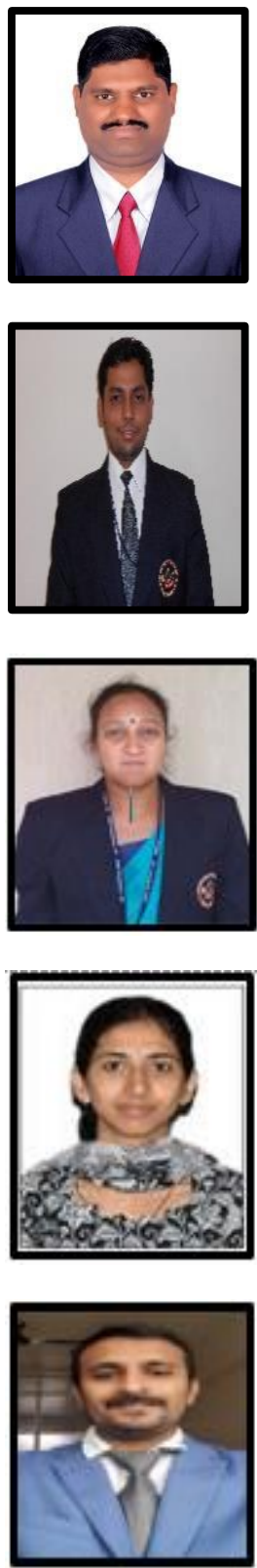

Dr. Manjunath T N, currently working as Professor in the department of information Science and Engineering, BMS Institute of Technology and Management, Bengaluru. He received his Bachelor's Degree in Computer Science and Engineering from Bangalore University, Bangalore, Karnataka, India during the year 2001 and M. Tech in Computer Science and Engineering from VTU, Belgaum, Karnataka, India during the year 2004. Ph.D from Bharathiar University (NIRF13), awarded in April-2015, Coimbatore, Tamil Nadu, India. He is having close to 20 years of Industry and teaching experience

Dr. Mallikarjunaswamy S, is currently working as an Associate Professor in Department of Electronics and Communication Engineering at JSS Academy of Technical Education, Bangalore. He obtained his B.E degree in Telecommunication Engineering from Visvesvaraya Technological University Belgaum in 2008, M. Tech degree from Visvesvaraya Technological University Belgaum in 2010 and was awarded Ph. D from Jain University in 2015.He has 11+ years of teaching experience. His research work has been published in more than 42 International Journals and conference. He received funds from different funding agencies. Currently guiding five research scholars in Visvesvaraya Technological University Belgaum.

Dr. Komala. M, is working as Associate Professor who has around 19 years of teaching experience and has published 30 papers in international and national journals, author of two books and has applied for two patents. She is presently guiding 3 research scholars. She has also attended and conducted many workshops, FDP, and conferences. Her area of interest is communication and networking.

Sharmila. $\mathbf{N}$ has completed her B.E in EEE at SJCE, Mysore and M. Tech in CAID at NIE Mysore. Secured second rank in Bachelor of Engineering degree. She has Eight years of experience in teaching and is currently working as an Assistant Professor in RNSIT, Bangalore.

Dr. Manu K S is currently working as Assistant Professor in the faculty of computer science and engineering department at SJBIT, Bengaluru under VTU. He obtained his Ph.D in image processing and VLSI from SSAHE, Tumkur. He also presented and published various academic as well as research-based papers at national conference, international conference and journals. His major research focused on Image processing, IoT protocols in real time applications, currently working on shadow detection and Protocols in real time system. 